Full-length article

\title{
Ginsenoside Rg1 promotes bone marrow stromal cells proliferation via the activation of the estrogen receptor-mediated signaling pathway ${ }^{1}$
}

\author{
Xin-zheng $\mathrm{LU}^{2,7}$, Jun-hong $\mathrm{WANG}^{2}$, Xin $\mathrm{WU}^{4}$, Lei $\mathrm{ZHOU}^{3}$, $\mathrm{Li}_{\mathrm{WANG}}{ }^{5}$, Xiao-wen $\mathrm{ZHANG}^{6}$, Ke-jiang $\mathrm{CAO}^{2}$, Jun \\ HUANG $^{2}$
}

${ }^{2}$ Department of Cardiology, the First Affiliated Hospital of Nanjing Medical University, Nanjing 210029, China; ${ }^{3}$ Department of Medicine, Baylor College of Medicine, Houston, Texas, USA; ${ }^{4}$ Department of Clinical Laboratory Medicine, Nanjing Benq Hospital, Nanjing 210029, China; ${ }^{5}$ Department of Internal Medicine, the Hospital Affiliated with Shanghai Meishan Group, Nanjing 210039, China; ${ }^{6}$ Department of Pharmacology, Nanjing Medical University, Nanjing 210029, China

\section{Key words}

ginsenoside Rg1; bone marrow stromal cell; estrogen receptor; proliferation

${ }^{1}$ This work was supported by the National Natural Science Foundation of China (№ 30370575), a post-doctoral grant of Jiangsu Province (№ 2004B21), and the Post-Graduate Innovation Projects of Jiangsu Province (№ JX22013013).

${ }^{7}$ Correspondence to Prof Xin-zheng LU.

Phn 86-25-8371-8836, ext 6325.

Fax 86-25-8367-3396.

E-mail xzlu@njmu.edu.cn

Received 2008-04-15

Accepted 2008-08-05

doi: $10.1111 /$ j.1745-7254.2008.00874.x

\begin{abstract}
Aim: To investigate the possible mechanisms of ginsenoside $\mathrm{Rg} 1$ promoting bone marrow stromal cell (BMSC) proliferation. Methods: BMSC were isolated from bone marrow of Sprague-Dawley rats and maintained in vitro. After stimulation with $1 \mu \mathrm{mol} / \mathrm{L}$ ginsenoside $\mathrm{Rg} 1$ for the indicated time, the proliferation ability of BMSC were assessed by 3-(4,5-dimethylthiazol-2-yl)-2,5diphenyltetrazolium bromide and $\left[{ }^{3} \mathrm{H}\right]$-thymidine incorporation assays. The estrogen receptor (ER) binding activity of BMSC was determined by a specific ER antagonist and an ER binding assay. Furthermore, the influence of ginsenoside Rg1 on the expression of ER $\alpha$ was investigated by RT-PCR and Western blotting assays. Results: BMSC proliferation stimulated by $1 \mu \mathrm{mol} / \mathrm{L}$ ginsenoside $\mathrm{Rg} 1$ can be completely blocked by $1 \mu \mathrm{mol} / \mathrm{L}$ ER antagonist ICI 182,780 , or ER $\alpha$ specific antagonist methylpiperidinopyrazole. Moreover, $\operatorname{Rg} 1$ failed to displace the specific binding of $\left[{ }^{3} \mathrm{H}\right] 17 \beta$-estradiol to BMSC cell lysates, suggesting that no direct interaction of $\mathrm{Rg} 1$ with the ER is needed for its estrogenic effects. In addition, $1 \mu \mathrm{mol} / \mathrm{L} \operatorname{Rg} 1$ had no effects on the expression of ER $\alpha$ in either the mRNA or protein levels. Conclusion: Our results indicate that ER $\alpha$ is essential for mediating the effects of $\mathrm{Rg} 1$ on stimulating BMSC proliferation, which might involve the ligand/receptor-independent activation of ER $\alpha$.
\end{abstract}

\section{Introduction}

The ginseng root, commonly used in traditional Chinese medicine, is widely studied in the West. It has been safely being used in China for more than 2000 years as a tonic against stress. Ginsenosides (steroidal glycosides), in the extracts of various kinds of ginsengs, are the major active components responsible for the pharmacological effects of ginseng on the central nervous, cardiovascular, endocrine, and immune systems ${ }^{[1-6]}$. There are 2 major classes of ginsenosides, protopanaxatriols ( $\mathrm{Rg} 1, \mathrm{Rg} 2, \mathrm{Re}$, and Rf) and protopanaxadiols (Rb1, Rb2, Rc, and Rd). They both possess 4 trans-ring rigid steroid skeletons with a modified side-chain at $\mathrm{C} 20$, which is absent in estradiol ${ }^{[7]}$.
Ginsenoside Rg1, a steroidal saponin abundantly contained in ginseng, is one of the most active components in ginseng and contributes to many of its effects.

Bone marrow stromal cells (BMSC) were initially identified in the bone marrow (BM) as multipotent, nonhematopoietic progenitor cells that can differentiate into osteoblasts, adipocytes, chondrocytes, tenocytes, skeletal myocytes, and visceral mesodermal cells ${ }^{[8-10]}$. BMSC can influence hematopoietic stem cell homing and differentiation through cell-cell interaction and by the production of cytokines and chemoattractants. They can also be used to regenerate bone, cartilage, myocardial, and hepatic tissues ${ }^{[10,11]}$. Since the autologous transplantation of BMSC does not generate immune response and has a limited ten- 
dency of tumorigenesis, BMSC have become ideal candidates for cell and gene therapies ${ }^{[12]}$.

Previously, we found that ginsenoside Rg1 could significantly promote the proliferation of cultured porcine BMSC in a dose-dependent manner ${ }^{[13]}$. This may be particularly ideal for accelerating the recovery of hematopoietic cells and protecting the bone micro-environment after chemotherapy or radiotherapy, facilitating the reconstruction of hematopoiesis after transplantation and promoting the ex vivo expansion of BMSC for cell and gene therapies. However, the underlying mechanisms of ginsenoside $\mathrm{Rg} 1$ promoting BMSC proliferation remain largely unknown. Since ginsenoside $\mathrm{Rg} 1$ is a kind of potent phytoestrogen ${ }^{[7]}$ which shares many targets with estrogens, we postulate that ginsenoside $\mathrm{Rg} 1$ might promote BMSC proliferation via the estrogen receptor (ER). Therefore, the ability of ginsenoside Rg1 to activate the ER in BMSC was assessed by using non-specific ER $\alpha$ or ER $\beta$ subunit antagonists ICI 182, 780, and specific ER $\alpha$ antagonist methylpiperidinopyrazole (MPP). In addition, the effects of ginsenoside $\operatorname{Rg} 1$ on BMSC ER $\alpha$ receptor expression were studied. Our findings indicated that ginsenoside Rg1 promoted BMSC proliferation and required $\mathrm{ER} \alpha$. However, ER $\alpha$ activation might be ligand/receptor independent.

\section{Materials and methods}

Isolation of BMSC The protocol was approved by the Committee of Animal Research at Nanjing Medical University (Nanjing, China). Eight-week-old male Sprague-Dawley (SD) rats were purchased from Shanghai SLAC Laboratory Animal Co, Ltd (Shanghai, China). BM was flushed from SD rat tibias and femurs using a 23-gauge needle. BM mononuclear cells were separated by gradient density centrifugation (Lymphoprep; Nycomed Pharma, Oslo, Norway) and cultured in Dulbecco's modified Eagle's medium (DMEM) supplemented with $20 \%$ fetal bovine serum (FBS), $100 \mathrm{U} / \mathrm{mL}$ penicillin, and $100 \mu \mathrm{g} / \mathrm{mL}$ streptomycin (GibcoBRL Life Technologies, USA) in 25$\mathrm{cm}^{2}$ flasks at $37{ }^{\circ} \mathrm{C}$ in a $5 \% \mathrm{CO}_{2}$ atmosphere. Seventy-two hours later, non-adherent cells were removed. Adherent cells were split at $70 \%-80 \%$ confluence $(0.05 \%$ trypsin at $37{ }^{\circ} \mathrm{C}$ for $5 \mathrm{~min}$; GibcoBRL Life Technologies, USA) and expanded in vitro. A homogenous cell population was obtained after 2-3 weeks of continuous culturing ${ }^{[13]}$.

BMSC proliferation assays To assess BMSC proliferation after the treatment of $1 \mu \mathrm{mol} / \mathrm{L}$ ginsenoside $\mathrm{Rg} 1$ (Sigma, St Louis, MO, USA), 3-(4,5-dimethylthiazol-2- yl)-2,5-diphenyltetrazolium bromide (MTT) and $\left[{ }^{3} \mathrm{H}\right]-$ thymidine incorporation assays were applied as previously described elsewhere ${ }^{[7,13]}$. Furthermore, in order to determine if ginsenoside $\mathrm{Rg} 1$ promotes BMSC proliferation via the ER, ER inhibitor ICI 182, 780, or MPP was added to the culture medium alone or $1 \mathrm{~h}$ before the addition of ginsenoside Rg1.

MTT assay BMSC were seeded onto 96-well plates $\left(3 \times 10^{3}\right.$ cells/well $)$ in phenol-red free DMEM supplemented with $10 \%$ FBS $24 \mathrm{~h}$ before treatment with or without 1 $\mu \mathrm{mol} / \mathrm{L} \mathrm{Rg} 1$ and $1 \times 10^{-7}, 1 \times 10^{-6}$, and $1 \times 10^{-5} \mathrm{~mol} / \mathrm{L}$ ICI 182 , 780 , or MPP. Forty-eight hours later, $100 \mu \mathrm{L}$ of $5 \mathrm{mg} / \mathrm{mL}$ MTT solution was added into each well. The plates were then incubated at $37{ }^{\circ} \mathrm{C}$ for $4 \mathrm{~h}$. In total, $100 \mu \mathrm{L}$ DMSO was added into each well and mixed thoroughly before reading on an ultra microplate reader (Bio-Tek Instruments, USA; wavelengths: test, $570 \mathrm{~nm}$; reference, $630 \mathrm{~nm}$ ).

$\left[{ }^{3} \mathrm{H}\right]$-thymidine incorporation assay We previously described the procedures for the $\left[{ }^{3} \mathrm{H}\right]$-thymidine incorporation assay. Briefly, BMSC were seeded onto 96-well plates at a density of $3 \times 10^{3}$ cells per well and grown in DMEM supplemented with $15 \%$ FBS for $7 \mathrm{~d}$. On the third day, half the medium was replaced with fresh growing medium, and the cells were treated with or without ginsenoside $\operatorname{Rg} 1(1 \mu \mathrm{mol} / \mathrm{L})$ and $1 \times 10^{-7}, 1 \times 10^{-6}$, and $1 \times 10^{-5} \mathrm{~mol} / \mathrm{L} \mathrm{ICI}$ 182,780 or MPP. Then, on the sixth day, $185 \mathrm{GBq} / \mathrm{L}$ of $\left[{ }^{3} \mathrm{H}\right]$ thymidine was added to each well and incubated for $24 \mathrm{~h}$. The cells were then rinsed with ice-cold phosphatebuffered saline (PBS) for 3-5 min and 10\% trichloroacetic acid for $30 \mathrm{~min}$. Finally, the cells were lysed in $200 \mu \mathrm{L}$ of $200 \mathrm{mmol} / \mathrm{L} \mathrm{NaOH}$ and left overnight at $4{ }^{\circ} \mathrm{C}$. Radioactivity was determined by scintillation counting.

ER binding assay The ER binding assay used in the present study was described elsewhere with slight modification ${ }^{[7]}$. Briefly, the BMSC were cultured in phenol red-free DMEM supplemented with 5\% charcoal-stripped FBS for $72 \mathrm{~h}$ before the cellular proteins were prepared. The cells were washed twice with ice-cold PBS and scraped off the flasks. The cells were suspended in PBS with 1 $\mathrm{nmol} / \mathrm{L}$ phenylmethylsulfonyl fluoride and $50 \mu \mathrm{mol} / \mathrm{L}$ protease inhibitor cocktail P8340 (Sigma, USA). The cells were then passed 20 times through a 26-gauge needle for complete breakage. The cell lysate was centrifuged, and the supernatant was used for the receptor binding assay. The final protein concentration in the binding assay was $1 \mathrm{mg} / \mathrm{mL}$ in a total volume of $500 \mu \mathrm{L}$ containing different concentrations of $\left[2,4,6,7-{ }^{3} \mathrm{H}\right]$ estradiol (GE Healthcare, USA) with or without a 500-fold excess of either nonlabeled estradiol or Rg1. Binding reactions were carried 
out at $4{ }^{\circ} \mathrm{C}$ for $24 \mathrm{~h}$ before the lysate-ligand mixture was mixed thoroughly with dextran-coated charcoal. The protein was then separated from the dextran-coated charcoal by centrifugation and transferred to scintillation vials for radioactivity measurement. Specific ligand binding was determined at each concentration of $17 \beta$-estradiol by subtracting the radioactive count in the vials containing both radiolabeled and cold ligand [displacement count (DC)] from the vials containing only the radiolabeled ligand [total binding (TB)]. The percentage of specific ligand binding was calculated as: $100 \% \times(\mathrm{TB}-\mathrm{DC}) / \mathrm{TB}$.

RT-PCR and Western blotting for ER $\alpha$ expression The cells were incubated with ginsenoside $\operatorname{Rg} 1$ for $30 \mathrm{~min}, 1,4$, and $8 \mathrm{~h}$ for the analysis of the expression of ER $\alpha$ in BMSC, After incubation, the BMSC were washed with cold PBS and harvested for RT-PCR and the Western blot analysis. For RT-PCR, total RNA was isolated from the cells by using TRIzol reagent. Total RNA was used to generate cDNA in each sample using SuperScript II reverse transcriptase with oligo(dT) 12-18 primers (Invitrogen, CA, USA). The expression of ER $\alpha$ was performed by semiquantitative RT-PCR. The primer sets for ER $\alpha$ and the housekeeping gene GAPDH were 5'-TGAAGCCTCAATGATGGG-3' (forward) and 5'-CAGGACTCGGTGGATGTG-3' (reverse) for ER $\alpha$, and 5'-TATCGGACGCCTGGTTA-3' (forward) and 5'-CATTTGATGTTAGCGGGAT-3' (reverse) for GAPDH to yield products of 424 and $222 \mathrm{bp}$, respectively. PCR amplification was performed on a GeneAmp 9600 PCR system (Perkin-Elmer, USA). The PCR products were analyzed using agarose gel electrophoresis. Optical densities of ethidium bromide-bound DNA bands were quantified using Quantity-One software (Bio-Rad, USA), and the mRNA expression levels were normalized to the expression of GAPDH. For Western blotting, the cells were lysed in $100 \mu \mathrm{L}$ RIPA sample buffer $[150 \mathrm{mmol} / \mathrm{L} \mathrm{NaCl}, 50 \mathrm{mmol} / \mathrm{L}$ Tris-HCl (pH 7.4), 1\% Nonidet P-40, $0.25 \%$ sodium deoxycholate, and $2 \mathrm{mmol} / \mathrm{L}$ orthovanadate]. Lysates were clarified, and protein contents were quantified by the Bradford method. Thirty micrograms of the clarified cell lysate was applied to $12 \%$ SDS-PAGE followed by transferring to a polyvinylidene difluoride membrane. The membrane was incubated with a monoclonal antibody against ER (Abcam, USA) and then with horseradish peroxidaseconjugated appropriate secondary antibodies followed by enhanced chemiluminescence reaction (Pierce, USA).

Statistical analysis Data were reported as mean \pm SEM. Significance of difference between group means was determined by one-way ANOVA. The independent Student's $t$-test was used to calculate statistical significance between the control group and each treatment group in the MTT and $\left[{ }^{3} \mathrm{H}\right]$-thymidine incorporation assays. A $P$-value $<0.05$ was considered statistically significant.

\section{Results}

With the exception of $1 \times 10^{-5} \mathrm{~mol} / \mathrm{L}$ MPP which presented cytotoxicity, in the absence of ginsenoside $\mathrm{Rg} 1$, the other compounds used did not affect the cell cultures. In general, the compounds used in this study did not have a dosedependent effect on the proliferative action of ginsenoside Rg1. The results presented here therefore only refer to the concentration of each drug that elicited the most effective response: $1 \times 10^{-6} \mathrm{~mol} / \mathrm{L}$ ICI 182780 , and $1 \times 10^{-6} \mathrm{~mol} / \mathrm{L} \mathrm{MPP}$.

Ginsenoside Rg1 stimulates rat BMSC proliferation The MTT and $\left[{ }^{3} \mathrm{H}\right]$ thymidine incorporation assays were used to evaluate the effects of ginsenoside $\operatorname{Rg} 1$ on the proliferative ability of BMSC in vitro. After incubation with $1 \mu \mathrm{mol} / \mathrm{L} \mathrm{Rg} 1$, the absorbency value of the cells increased significantly $(0.38 \pm 0.05$ vs $0.68 \pm 0.07 ; P<0.01)$. The thymidine incorporation value was enhanced from $3569.80 \pm 809.75$ to $8321.00 \pm 2408.42(P<0.01$; Table 1$)$.

Role of ER in mediating ginsenoside Rg1 action The binding of $\left[{ }^{3} \mathrm{H}\right] 17 \beta$-estradiol to BMSC lysates in the presence and absence of a 500-fold excess of cold Rg1 and $17 \beta$-estradiol was determined. In the case of $17 \beta$-estradiol, a 500 -fold excess of cold ligand was sufficient to displace the specific binding of $\left[{ }^{3} \mathrm{H}\right] 17 \beta$-estradiol with its receptor in the BMSC cell lysates. Figure 1 demonstrates the percentage of specific binding of $17 \beta$-estradiol at different concentrations of $17 \beta$-estradiol. In contrast, $0.1 \mu \mathrm{mol} / \mathrm{L}$ non-labeled $\operatorname{Rg} 1$ failed to displace the specific binding of

Table 1. Effects of Rg1, ICI 182, 780, and MPP on BMSC proliferation in rats. $n=10$. mean \pm SEM (Student's $t$-test). ${ }^{\mathrm{b}} P<0.05$, ${ }^{\mathrm{c}} P<0.01 v s$ control.

\begin{tabular}{lcccrrr}
\hline \multicolumn{1}{c}{ Assay } & Control & Rg1 & Rg1+ICI 182 780 & Rg1+MPP & ICI 182 780 & MPP \\
\hline MTT (OD 570 value) & $0.38 \pm 0.05$ & $0.68 \pm 0.07^{\mathrm{c}}$ & $0.37 \pm 0.08$ & $0.36 \pm 0.07$ & $0.33 \pm 0.06$ & $0.31 \pm 0.07$ \\
$\begin{array}{l}\left.{ }^{3} \mathrm{H}\right] \text {-thymidine } \\
\text { incorporation }(\mathrm{cpm})\end{array}$ & $3569.80 \pm 809.75$ & $8321.00 \pm 2408.42^{\mathrm{c}}$ & $3690.70 \pm 921.90$ & $3759.30 \pm 826.00$ & $3367.60 \pm 783.71$ & $3403.03 \pm 854.66^{\mathrm{b}}$ \\
\hline
\end{tabular}




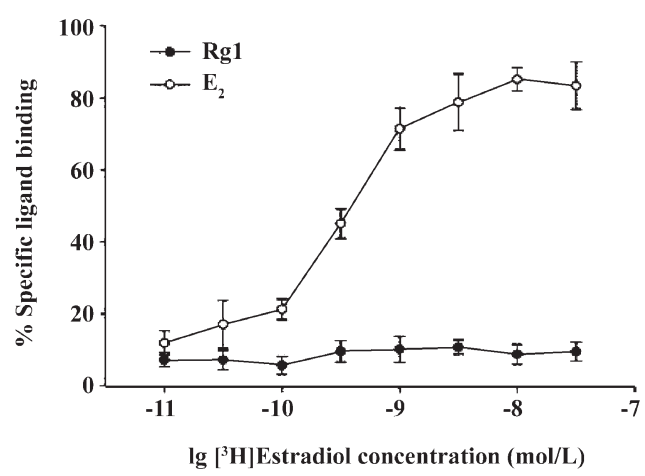

Figure 1. ER binding assay. Total $\left[{ }^{3} \mathrm{H}\right]$ estradiol binding to the BMSC cellular protein was determined at different concentrations of radiolabeled ligand in the absence of non-labeled competitor. Radioactive counts were also measured in the presence of a 500 -fold molar excess of either nonlabeled estradiol or Rg1 attempting displacement of $\left[{ }^{3} \mathrm{H}\right] 17 \beta$-estradiol $\left(\mathrm{E}_{2}\right)$ from ER. Percentage of specific ligand binding was calculated based on the following equation: $100 \% \times(\mathrm{TB}-\mathrm{DC}) / \mathrm{TB}$. Data are the mean of $\mathrm{du}-$ plicate determinations, and the experiment was repeated twice. Specific binding of $17 \beta$-estradiol increases with increasing doses of $17 \beta$-estradiol. No specific binding of $\operatorname{Rg} 1$ to ER was found at any concentration of $17 \beta$-estradiol tested.

$\left[{ }^{3} \mathrm{H}\right] 17 \beta$-estradiol with its receptor, which indicated that no direct interaction existed between $\mathrm{ER} \alpha$ and $\mathrm{Rg} 1$ at concentrations as high as $1 \mu \mathrm{mol} / \mathrm{L}$. However, when pretreated with $1 \times 10^{-6} \mathrm{~mol} / \mathrm{L}$ ICI 182,780 , or MPP, the MTT and $\left[{ }^{3} \mathrm{H}\right]$-thymidine incorporation assays demonstrated that both ICI 182, 780, and MPP could completely repress the proliferative ability of BMSC stimulated by ginsenoside
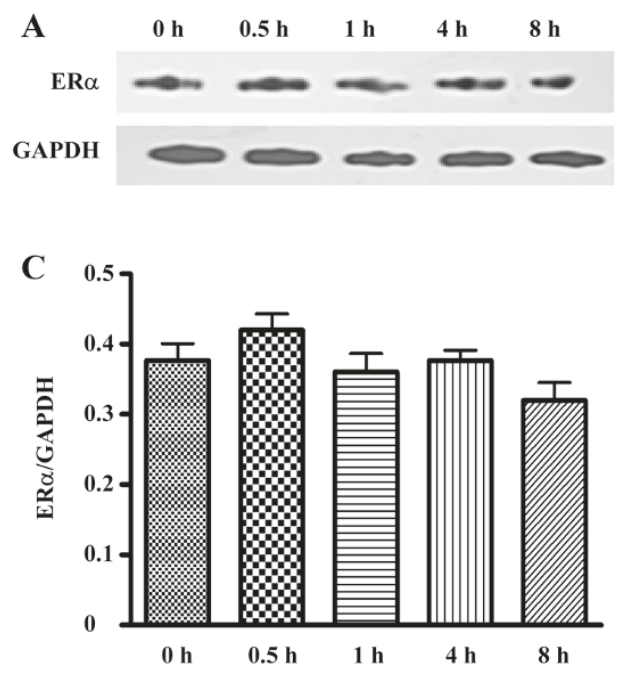

$\operatorname{Rg} 1$, as shown in Table 1.

Role of ginsenoside Rg1 on the expression of ER $\alpha$ in BMSC As ICI 182, 780, and MPP showed similar action on ginsenoside Rg1-induced BMSC proliferation, we therefore supposed that ER $\alpha$, not ER $\beta$, was an essential mediator of $\operatorname{Rg} 1$ action. We then examined if $\operatorname{Rg} 1$ exerted $\mathrm{E}_{2}$-like activity by regulating the expression level of ER $\alpha$ in BMSC. As ER $\alpha$ was the major isomer expressed in BMSC, we studied its expression in response to $\mathrm{Rg} 1$ in the present study. As shown in Figure 2, the time-course response effects of $\mathrm{Rg} 1$ on the $\mathrm{ER} \alpha$ protein and mRNA expressions were determined. Our results showed that 1 $\mu \mathrm{mol} / \mathrm{L} \mathrm{Rg} 1$ did not significantly alter the ER $\alpha$ protein expression. Similarly, its mRNA expression level in BMSC was unaltered in response to treatment with $1 \mu \mathrm{mol} / \mathrm{L} \mathrm{Rg} 1$. Thus it appears that $\operatorname{Rg} 1$ behaves differently from $\mathrm{E}_{2}$ and does not change the expression of ER $\alpha$ in BMSC.

\section{Discussion}

Ginsenoside $\operatorname{Rg} 1$ is a steroid saponin that shares similar structural features and targets organs with steroid hormones ${ }^{[1]}$. Ginsenosides are amphiphilic in nature and have the ability to intercalate into the plasma membrane. There is evidence suggesting that ginsenosides interact directly with specific membrane proteins ${ }^{[14,15]}$. Moreover, like steroid hormones, $\operatorname{Rg} 1$ has previously been shown to interact with the glucocorticoid receptor and initiate genomic effects $^{[16,17]}$.
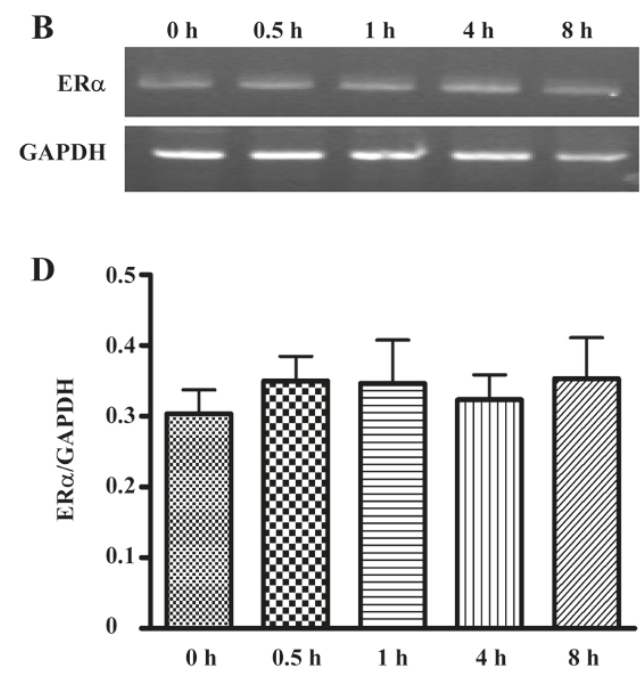

Figure 2. Effect of $\operatorname{Rg} 1$ on the $\mathrm{ER} \alpha$ protein and $\mathrm{ER} \alpha$ mRNA expressions. BMSC were treated with $1 \mu \mathrm{mol} / \mathrm{L} \operatorname{Rg} 1$ with increasing time $(0,0.5,1,4$, and $8 \mathrm{~h}$ ). Representative protein and total RNA were isolated and subjected to Western blotting (A) and RT-PCR (B) analyses. ER $\alpha$ protein (C) and mRNA (D) expression levels are presented, which are expressed as a ratio to the expression of GAPDH, respectively. Results were obtained from 3 independent experiments and expressed as mean \pm SEM. $n=3$. 
BMSC are the precursors of different mesenchymal tissues that play a crucial role in the construction of normal and pathological microenvironments. Previously, we observed that ginsenoside $\operatorname{Rg} 1$ could greatly enhance $e x$ vivo BMSC proliferation in a dose-dependent manner, and $1 \mu \mathrm{mol} / \mathrm{L} \operatorname{Rg} 1$ was sufficient to enhance the maximum proliferation of $\mathrm{BMSC}^{[13]}$. So in the present study, we chose $1 \mu \mathrm{mol} / \mathrm{L}$ as the appropriate concentration for $\operatorname{Rg} 1$ to stimulate the proliferation of BMSC. Because BMSC play important roles in hemopoiesis and in regulating the body's immunoreactivity, the ability of ginsenoside $\operatorname{Rg} 1$ to enhance BMSC proliferation is of potential value for clinical application. Previous studies have shown that Rg1 has estrogen-like properties and exerts its action via the activation of ER $\alpha$ in human breast cancer MCF-7 cells ${ }^{[7]}$. As considerable evidence has indicated that of the $2 \mathrm{ER}$ ( $\alpha$ and $\beta$ ), ER $\alpha$ is most likely the dominant ER regulating bone metabolism, at least in mice ${ }^{[18]}$. In the present study, $\mathrm{ER} \alpha$ was abundantly expressed in $\mathrm{BMSC}^{[19]}$, so we postulated that ginsenoside $\mathrm{Rg} 1$ might also exhibit an estrogenlike effect on the proliferation of BMSC via ER $\alpha$. After ginsenoside Rg1 treatment, the BMSC demonstrated significant proliferative ability, which was consistent with our previous study. In total, $1 \mu \mathrm{mol} / \mathrm{L}$ ginsenoside $\mathrm{Rg} 1$ treatment led to more protein synthesis, which was proven by the MTT and $\left[{ }^{3} \mathrm{H}\right]$-thymidine incorporation assays. As anticipated, BMSC proliferation stimulated by ginsenoside $\mathrm{Rg} 1$ could be completely abolished by a pretreatment with a pure ER antagonist, ICI 182, 780, or ER $\alpha$-specific antagonist MPP, which indicates that ER $\alpha$ may be the key subunit for $\mathrm{Rg} 1$ to exert its action on BMSC. However, unlike $\mathrm{E}_{2}$ and other phytoestrogen, such as genistein ${ }^{[20]}$, Rg1 did not directly bind to ER and change the expression of ER $\alpha$ in BMSC, which was confirmed by RT-PCR and Western blotting. Thus the increase in $\mathrm{E}_{2}$-like activity by $\operatorname{Rg} 1$ in BMSC appears to activate ER $\alpha$ through its downstream signaling molecular activation. Lau found that $\mathrm{Rg} 1$ could activate ER $\alpha$ via the phosphorylation of the AF-1 domain of ER $\alpha$ at serine 118 residue and exert estrogen-like activities ${ }^{[21]}$. Moreover, Sims et al demonstrated the involvement of the crosstalk between ER(insulin-like growth factor)IGF-insulin resistance (IR)dependent signaling pathways in mediating the actions of Rg1 in MCF-7 cells ${ }^{[22]}$, while other researchers found that genistein, the soybean phytoestrogen, promoted mouse BMSC proliferation and osteoblastic maturation via the nitric oxide (NO)/GC-mediated pathway ${ }^{[23]}$. Therefore, the involvement of other signaling pathways, such as the IGF-IR-dependent pathway or NO/GC pathway in BMSC requires further study.

In summary, the present study provides a new paradigm for characterizing the molecular actions of ginsenoside $\mathrm{Rg} 1$ on the proliferative ability of BMSC. Similar to the action of MCF-7 cells, the $\mathrm{E}_{2}$-like activities of ginsenoside $\mathrm{Rg} 1$ are not mediated by direct binding interaction with ER $\alpha$. Most importantly, our results show that ER is essential for mediating the actions of $\mathrm{Rg} 1$ in the stimulation of BMSC proliferation. Future studies will be needed to delineate the detailed mechanism of action of ginsenosides in BMSC, as well as to provide insights for understanding the complex actions of ginseng extract in the human body.

\section{Author contribution}

Xin-zheng LU designed research; Jun-hong WANG, Xin WU, and Li WANG performed research; Li WANG, contrbuted new analytical tools and reagents; Xiao-Wen ZHANG analyzed data; Jun-hong WANG and Lei ZHOU wrote the paper.

\section{References}

1 Attele AS, Wu JA, Yuan CS. Ginseng pharmacology: multiple constituents and multiple actions. Biochem Pharmacol 1999; 58: 168593.

2 Beloti MM, Bellesini LS, de Oliveira PT, Rosa AL. Participation of estrogen receptors in the enhancement of osteoblast differentiation by TAK-778. Mol Cell Biochem 2006; 285: 101-9.

3 Brann DW, Hendry LB, Mahesh VB. Emerging diversities in the mechanism of action of steroid hormones. J Steroid Biochem Mol Biol 1995; 52: 113-33.

4 Chan RY, Chen WF, Dong A, Guo D, Wong MS. Estrogen-like activity of ginsenoside Rg1 derived from Panax notoginseng. J Clin Endocrinol Metab 2002; 87: 3691-5.

5 Chen WF, Lau WS, Cheung PY, Guo DA, Wong MS. Activation of insulin-like growth factor I receptor-mediated pathway by ginsenoside Rg1. Br J Pharmacol 2006; 147: 542-51.

6 Chen WF, Wong MS. Genistein enhances insulin-like growth factor signaling pathway in human breast cancer (MCF-7) cells. J Clin Endocrinol Metab 2004; 89: 2351-9.

7 Cheng Y, Shen LH, Zhang JT. Anti-amnestic and anti-aging effects of ginsenoside Rg1 and Rb1 and its mechanism of action. Acta Pharmacol Sin 2005; 26: 143-9.

8 Cho WC, Chung WS, Lee SK, Leung AW, Cheng CH, Yue KK. Ginsenoside Re of Panax ginseng possesses significant antioxidant and antihyperlipidemic efficacies in streptozotocin-induced diabetic rats. Eur J Pharmacol 2006; 550: 173-9.

9 Jiang Y, Jahagirdar BN, Reinhardt RL, Schwartz RE, Keene CD, Ortiz-Gonzalez XR, et al. Pluripotency of mesenchymal stem cells derived from adult marrow. Nature 2002; 418: 41-9.

10 Kimura T, Saunders PA, Kim HS, Rheu HM, Oh KW, Ho IK. Interactions of ginsenosides with ligand-bindings of $\operatorname{GABA}(\mathrm{A})$ and GABA(B) receptors. Gen Pharmacol 1994; 25: 193-9. 
11 Krampera M, Pasini A, Rigo A, Scupoli MT, Tecchio C, Malpeli G, et al. HB-EGF/HER-1 signaling in bone marrow mesenchymal stem cells: inducing cell expansion and reversibly preventing multilineage differentiation. Blood 2005; 106: 59-66.

12 Lau WS, Chan RY, Guo DA, Wong MS. Ginsenoside Rg1 exerts estrogen-like activities via ligand-independent activation of ERalpha pathway. J Steroid Biochem Mol Biol 2008; 108: 64-71.

13 Lu XZ, Zhang XW, Huang J, Ma GS, Hou MH. Effect of ginsenoside Rg1 on multiplication of pig's bone marrow stromal cells in vitro. Chin J Clin Rehab 2005; 9: 143-5.

14 Leung KW, Pon YL, Wong RN, Wong AS. Ginsenoside-Rg1 induces vascular endothelial growth factor expression through the glucocorticoid receptor-related phosphatidylinositol 3-kinase/Akt and betacatenin/T-cell factor-dependent pathway in human endothelial cells. J Biol Chem 2006; 281: 36 280-8.

15 Lee YJ, Chung E, Lee KY, Lee YH, Huh B, Lee SK. Ginsenoside$\mathrm{Rg} 1$, one of the major active molecules from Panax ginseng, is a functional ligand of glucocorticoid receptor. Mol Cell Endocrinol 1997; 133: 135-40.

16 Orlic D, Kajstura J, Chimenti S, Jakoniuk I, Anderson SM, Li B, et al. Bone marrow cells regenerate infarcted myocardium. Nature 2001; 410: 701-5.
17 Pan W, Quarles LD, Song LH, Yu YH, Jiao C, Tang HB, et al. Genistein stimulates the osteoblastic differentiation via NO/cGMP in bone marrow culture. J Cell Biochem 2005; 94: 307-16.

18 Poindexter BJ, Allison AW, Bick RJ, Dasgupta A. Ginseng: Cardiotonic in adult rat cardiomyocytes, cardiotoxic in neonatal rat cardiomyocytes. Life Sci 2006; 79: 2337-44.

19 Prockop DJ, Gregory CA, Spees JL. One strategy for cell and gene therapy: harnessing the power of adult stem cells to repair tissues. Proc Natl Acad Sci USA 2003; 100 Suppl 1: 11 917-23.

20 Radad K, Gille G, Liu L, Rausch WD. Use of ginseng in medicine with emphasis on neurodegenerative disorders. J Pharmacol Sci 2006; 100: 175-86.

21 Sengupta S, Toh SA, Sellers LA, Skepper JN, Koolwijk P, Leung HW, et al. Modulating angiogenesis: the yin and the yang in ginseng. Circulation 2004; 110: 1219-25.

22 Sims NA, Dupont S, Krust A, Clement-Lacroix P, Minet D, RescheRigon $\mathrm{M}$, et al. Deletion of estrogen receptors reveals a regulatory role for estrogen receptors-beta in bone remodeling in females but not in males. Bone 2002; 30: 18-25.

23 Smith JR, Pochampally R, Perry A, Hsu SC, Prockop DJ. Isolation of a highly clonogenic and multipotential subfraction of adult stem cells from bone marrow stroma. Stem Cells 2004; 22: 823-31. 